\title{
Grupos de Convivência: contribuições para uma proposta educativa em Tuberculose
}

\author{
Living Groups: contributions for an educational proposal for Tuberculosis \\ Grupos de Convivencia: contribuciones para un propuesta educativa en Tuberculosis
}

\section{Sabrina da Silva de Souza}

Enfermeira. Mestranda em Enfermagem na Universidade Federal de Santa Catarina. Integrante do NUCRON, Florianópolis, SC.

\section{Denise Maria Guerreiro Vieira da Silva}

Enfermeira. Doutora em Enfermagem.

Professora Adjunto do Departamento de

Enfermagem e do Programa de PósGraduação em Enfermagem da Universidade Federal de Santa Catarina. Coordenadora do NUCRON, Florianópolis, SC

Trabalho desenvolvido na disciplina "Projetos Assistenciais de Enfermagem e de Saúde" do Mestrado em Enfermagem do Programa de Pós-Graduação em Enfermagem da UFSC.
Submissão: 13/06/2006

Aprovação: 13/02/2007

\section{RESUMO}

Trata-se de um relatório de prática assistencial que teve como objetivo desenvolver uma proposta de educação em saúde com grupo de pessoas com tuberculose, visando a efetivação do tratamento. Os dados foram obtidos através de uma proposta de educação em saúde, desenvolvida em um grupo de convivência. Decorrentes do processo de análise foram identificados dois temas que estavam interligados: a percepção da tuberculose e seus cuidados e tratamentos e 0 isolamento social ,que representam os elementos que influenciam na educação em saúde das pessoas com tuberculose e 0 significado que a mesma traz para essas pessoas.

Descritores: Tuberculose; Tratamento primário; Educação em saúde.

\section{ABSTRACT}

This study is a report on care practice. Its objective was to develop a proposal for education in health care from a group of people with tuberculosis, seeking to increase the effectiveness of their treatment. The data was obtained through a proposal for education in health care, developed through a living group. Two interrelated themes resulted from the process of analyzing the data: the perception of tuberculosis and its care and treatment, and social isolation. These represent the elements that influence education in health care for people with tuberculosis, as well as the meaning that such a situation has to these people.

Descriptors: Tuberculosis; Primary treatment; Health education.

\section{RESUMEN}

Se trata de um retatorio de practica asistencial que teivo como objetivo desenvolver uma propuesta de educación em salud com um grupo de personas com tuberculosis, visando que el tratamiento se a mas efectivo. Los datos fueram obtenidos atravéz de una propuesta de educación en salud, desenvolvida en un grupo de convivencia. Decorrentes del proceso de análisis fueram identificados dos temas que estavam interligados: la percepción de la tuberculosis, sus cuidados y tratamiento y el aislamiento social, que representam los elementos que influenciam en la educación in salud de las personas con tuberculosis e el significado que la misma trae para estas personas.

Descriptores: Tuberculosis; Tratamiento primario; Educación em salud.

Souza SS, Silva DMGV. Grupos de Convivência: contribuições para uma proposta educativa em Tuberculose. Rev Bras Enferm 2007 set-out; 60(5): 590-5.

\section{INTRODUÇÃO}

Estudos antropológicos e sociológicos vêm, há tempos, explorando o domínio da construção social e simbólica da doença nas mais diversas sociedades. Para toda a sociedade, a doença é um problema que exige explicação, é necessário que ela tenha um sentido. É preciso avaliar a dimensão social da doença, como ela se mostra, pois a doença funciona como significante social, é uma das expressões da sociedade ${ }^{(1)}$.

Até a descoberta do bacilo de Koch, em 1882, atribuía-se a tuberculose a uma doença de origem hereditária. Em geral quando uma pessoa adoecia, vários membros da família também adoeciam. Não se percebia naquela época que o confinamento familiar é que favorecia a propagação da doença na família(2).

Discutindo a metaforização da tuberculose no século XIX, mostra que essa doença, tida como misteriosa e incurável, despertava vários tipos de pavor, todos na verdade, referentes a temas e 
problemas sociais que, pouco ou nada tinham a ver propriamente com 0 universo da ciência ${ }^{(2)}$.

Assim como a hanseníase, a tuberculose chama a atenção devido à sua prevalência e intensidade nas mais diferentes sociedades através de diversos períodos históricos(3).

Nenhuma outra doença incitou tanto os estudiosos, profissionais da saúde, juristas, administradores públicos, religiosos, escritores de ficção e pesquisadores em geral quanto a tuberculose. (...) a tísica favoreceu, na linha histórica a elaboração de um campo conceitual próprio que, estendido aos seus tributários, promoveu sucessivos conflitos de perspectivas e interesses, resultando no mosaico de interpretações sobre a doença e 0 doente ${ }^{(4)}$.

As definições atuais que permitem a compreensão clínica-epidemiológica da tísica são fruto de uma história marcada pela paixão e pela necessidade. Paixão porque a persistência do enigma patológico se impôs como desafio que exigia respostas clareadoras em conseqüência, o passado da medicina está repleto de interpretações sobre os mecanismos da doença do peito e as possíveis decisões terapêuticas ${ }^{(4)}$.

A experiência profissional ${ }^{5}$ mostra que portadores de tuberculose pulmonar sofrem com a aquisição desta doença, não só pelas manifestações clínicas, mas também pela possibilidade de vivenciar preconceitos e rejeitando conseqüentemente as relações sociais em geral.

Tendo em vista a progressão da doença, mesmo depois de um longo período de estabilidade, a tuberculose vem sendo caracterizada como uma doença crônica ressurgente, levando os seus portadores a experienciarem preconceitos ou até mesmo isolamento social(5).

A tuberculose é a 9a causa de internações por doenças infecciosas, ocupa $07^{\circ}$ lugar em gastos com internação (SUS) por doenças infecciosas e é a $4^{a}$ causa de mortalidade por doenças infecciosas no Brasil( ${ }^{(6)}$.

A propagação da tuberculose está intimamente ligada às condições de vida da população. Prolifera, como todas as doenças infecciosas, em áreas de grande concentração humana, com falta de infra-estrutura, saneamento, onde coexistem a fome e a miséria. Por isto sua incidência é maior nas periferias das cidades, porém pode acometer qualquer pessoa independente de sua moradia. Neste sentido atenção especial deve ser dada a populações de maior risco de adoecimento, representada, sobretudo por residentes em comunidades fechadas, como presídios, manicômios, asilos. Também se incluem os imunodreprimidos por uso de medicamentos ou por doenças imunossupressora(7).

As representações de saúde/doença e as concepções sobre a etiologia e o contágio da tuberculose demonstram que a sabedoria prática das pessoas com tuberculose não se restringe aos ensinamentos biomédicos, pelo contrário, há um amplo leque de possibilidades que fogem ao serviço $\operatorname{prestado}^{(8)}$.

Sontag ${ }^{(1)}$ em seu estudo sobre a tuberculose e 0 câncer traça um comparativo entre estas duas doenças, analisa a utilização irreal e muitas vezes primitiva, em nossa cultura, da doença em sentido figurado, da doença como metáfora. Seu ponto de vista é o de que a enfermidade não é uma metáfora e que o modo mais verdadeiro de encarar a doença e a maneira mais saudável de ficar doente é resistir a esses pensamentos metafóricos. As fantasias florescem, por que o câncer e a tuberculose são vistos como algo muito além da sua condição de doenças possivelmente fatais.

As representações sobre a doença são produzidas e reelaboradas constantemente. Os significados a respeito da doença são construídos através da convivência rotineira no ambiente das instituições de saúde. As representações sobre a doença são determinadas pelas condições sociais de inserção dos sujeitos sociais ${ }^{(9)}$.

A tuberculose é uma doença infecto-contagiosa que, de regra, assume evolução crônica e tem como agente etiológico o Mycobacterium tuberculosis ${ }^{(4)}$, que, na sua forma pulmonar, é transmitida de pessoa a pessoa por um bacilo álcool-ácido resistente (BAAR), o Mycobacterium tuberculosis, ou Bacilo de Koch (BK) ${ }^{(6)}$. Acompanha a espécie humana desde os primórdios da história, sendo que se apresenta como um dos problemas que mais têm preocupado as autoridades sanitárias de todo 0 mundo, devido a sua crescente incidência em diferentes grupos populacionais ${ }^{(10)}$.

Estima-se que mais de 50 milhões de brasileiros estejam infectados pelo bacilo da tuberculose. Calcula-se o surgimento de 110.000 novos casos de tuberculose a cada ano, sendo que somente em torno de 80.000 serão notificados. O número de óbitos por tuberculose no Brasil ultrapassa os 6.000 casos por ano. 0 percentual de cura dos casos tratados é de apenas $72 \%$ quando deveria ser, no mínimo, de $85 \%$. O Brasil ocupa o $15^{\circ}$ lugar entre os 22 países responsáveis por $80 \%$ do total de casos de TB no mundo(6).

Atualmente, o maior problema apontado no tratamento da tuberculose é a não adesão; por conseqüência os índices de incidência, mortalidade e de tuberculose multirresistente estão aumentando.

O tratamento prolongado, as reações adversas no uso das drogas antituberculose, a melhora clínica nos primeiros três meses de tratamento, 0 forte estigma ainda presente em relação à tuberculose são os principais fatores que contribuem para o não seguimento do tratamento. As experiências têm demonstrado que os esquemas terapêuticos disponíveis são efetivos em relação ao processo de cura, porém, na prática, os rendimentos insatisfatórios se devem a problemas políticos, administrativos, sociais e assistenciais.

As representações de saúde/doença e as concepções sobre a etiologia e o contágio da tuberculose demonstram que a sabedoria prática das pessoas com tuberculose não se restringem aos ensinamentos biomédicos, pelo contrário, há um amplo leque de possibilidades que fogem ao serviço prestado(8). Esta percepção da pessoa com tuberculose e o envolvimento do contexto social no seu comportamento amplia a discussão para além dos aspectos clínicos.

O convívio com outras pessoas com tuberculose durante o processo de tratamento, de modo geral não é regular. Esta situação traz a sensação de solidão e de que experimentam uma situação única, desconhecendo como outras pessoas com tuberculose enfrentam sua condição. Compreendemos que possibilitar o encontro e o convívio mais próximo das pessoas com tuberculose pode promover o conhecimento mútuo dos dramas vivenciados cotidianamente, possibilitando às pessoas sentimentos de solidariedade e principalmente uma referência no sentido de que o indivíduo se dá conta de que não está sozinho naquela situação e, na confrontação com o outro, ele avalia suas possibilidades de superação da doença e reflete sobre sua vida. Essa ação de provocar o compartilhar de experiências integra o processo de educação em saúde e envolve, portanto, a necessidade de que os profissionais da saúde tenham um conhecimento abrangente que vai além dos aspectos clínicos e fisiopatológicos, mas que inclui a compreensão do que é viver com a tuberculose.

O processo educativo em grupo, valoriza a aproximação das pessoas, favorece o fortalecimento das potencialidades individuais e também grupais, na valorização da saúde, na utilização dos recursos disponíveis e no exercício da cidadania ${ }^{(11)}$.

No que tange aos aspectos educativos nossa referência tem sido em Paulo Freire, pelo enfoque que o mesmo dá ao ser humano no qual permeia a questão ética de valor e respeito ao outro, pois, acreditamos que seus ensinamentos a cerca da educação possibilitam o desenvolvimento da educação em saúde de maneira dialógica e promovendo a autonomia das pessoas.

O diálogo é o instrumento do processo educativo e para que ele seja estabelecido é necessário que ocorra uma relação de empatia, que seja amorosa, critica, confiante, esperançosa e criadora. O diálogo é o encontro dos homens em que se solidarizam o refletir e 0 agir de seus sujeitos ${ }^{(12)}$.

Nossas idéias estão em harmonia com as de Freire ${ }^{(13)}$ quando coloca que a educação que se impõe aos que verdadeiramente se comprometem 
com a libertação não pode fundar-se numa compreensão dos homens como seres "vazios" a quem o mundo "encha" de conteúdos; não pode basear-se numa consciência espacializada, mecanicistamente compartimentada, mas nos homens como "corpos conscientes" e na consciência como consciência intencionada ao mundo. Não pode ser a do depósito de conteúdos, mas a da problematização dos homens em suas relações com o mundo ${ }^{(13)}$.

Assim, acreditamos que a proposta de educação em grupo cria possibilidades para as pessoas para que percebam criticamente a sua realidade e as suas necessidades, desenvolvam as suas potencialidades e busquem, num trabalho conjunto, os meios para as possíveis resoluções de seus problemas de saúde de forma consciente e efetiva.

O espaço do grupo pode facilitar o encontro entre pares, na medida em que, propiciando este "mostrar-se igual", supera-se o individualismo presente até então. $\mathrm{O}$ homem está no mundo e com o mundo, pois se apenas estivesse no mundo não objetivaria a si mesmo. Objetivando, pode distinguir entre um eu e u não eu, fazendo o capaz de relacionar-se, de sair de si, de projetar-se nos outros, de transcender ${ }^{(14)}$.

No processo educativo em grupo, as principais vantagens identificadas são: possibilidade de conhecer e compartilhar com outras pessoas com tuberculose a mesma condição de saúde, sentimentos e modo de conviver com a doença. $O$ grupo é mais adequado para aprofundar a educação, favorece a mudança de comportamento.

A proposta deste estudo nasce da convergência dos aspectos até aqu apresentados, uma vez que desenvolvemos um estudo com as pessoas integrantes de um Programa de Controle da Tuberculose, focalizando a compreensão do viver com tuberculose, com a intenção de contribuir para a construção de uma proposta educativa aderente às necessidades das pessoas que vivenciam esta condição.

\section{OBJETIVO}

Desenvolver uma proposta de educação em saúde com um grupo de pessoas com tuberculose, em um município de Santa Catarina visando à efetivação do tratamento.

\section{CAMINHO METODOLÓGICO}

\subsection{Local}

A prática assistencial foi realizada em um serviço de referência no Controle de Tuberculose num município de Santa Catarina.

\subsection{Sujeitos da Prática}

Os sujeitos da prática foram cinco pessoas com tuberculose pulmonar e/ou extrapulmonar, atendidas no programa de controle de tuberculose no período de setembro a novembro de 2005. Destas 04 eram mulheres e 01 homem, com idade entre 50 e 65 anos.

A escolha dos sujeitos foi intencional. Foram convidados os integrantes do Programa com idade acima de 18 anos e que expressaram disponibilidade em participar da prática educativa. Esses convites foram efetuados durante as consultas de enfermagem.

\subsection{Desenvolvimento da Prática}

A implementação da prática assistencial ocorreu através do grupo de convivência. $\mathrm{O}$ grupo de convivência provoca educação participativa, concretizando-se quando a enfermeira se envolve e se compromete com 0 crescimento do grupo de tal forma que todos se mostrem ativos no trabalho em grupo ${ }^{(15)}$. Esta técnica de grupos de convivência é propícia para abandonar a tradicional postura diretiva e assumir a postura participativa em sua prática assistencial. Esse trabalho em se tratando de prevenção em saúde pode produzir multiplicadores do saber aprendido ${ }^{(16)}$.

Nos grupos de convivência procuramos compartilhar experiências sobre o viver com tuberculose. Foram discutidas as facilidades e dificuldades da adesão ao tratamento, buscando a tomada de consciência sobre a realidade e possibilidades de transformação.

O grupo de convivência teve uma proposta de educação em saúde participativa, onde foram problematizados os temas que emergiram no grupo.

O processo de desenvolvimento do grupo seguiu as 4 fases de formação: fase do reconhecimento, fase da revelação, fase do repartir e do repensar ${ }^{(17)}$.

A fase do reconhecimento incluiu o convite aos participantes e a apresentação inicial dos integrantes do grupo. A fase de revelação compreendeu a exteriorização das expectativas, desejos, sentimentos, necessidades, aspirações e opiniões. Na fase do repartir ocorreu a troca de experiências em relação aos temas geradores que foram problematizados. O repensar foi à reflexão dos participantes sobre o processo experienciado e a proposição de novas perspectivas sobre o viver com tuberculose. Estas fases ocorreram naturalmente e se inter-relacionaram e contribuiram para uma análise do processo educativo desenvolvido no grupo.

\subsection{Aspectos éticos}

A relação da ética com a educação em saúde mostra e salienta a importância de se respeitar a dinâmica social, percebendo o ser humano enquanto ser social em constante mudança, na busca de formas de agir próxima aos princípios éticos universais.

Devemos refletir sobre as conseqüências de nossos julgamentos, das nossas decisões e ações, ou seja, no poder de nossa intervenção na vida de outras pessoas. Durante a prática desenvolvida procuramos manter um diálogo aberto com os integrantes, avaliando constantemente nossas ações na condução do grupo de maneira a perceber como poderíamos estar interferindo na vida daquelas pessoas e se isso poderia lhes trazer qualquer prejuízo ${ }^{(18)}$

Nesse processo, os princípios éticos de beneficência, respeito pela dignidade humana e justiça foram os principais orientadores da prática educativa.

Utilizamos linguagem clara e objetiva favorecendo assim a compreensão por parte dos sujeitos da prática assistencial. Aautorização foi obtida através do Termo de Consentimento Livre e Esclarecido, que foi identificado, assinado e datado. Foi garantida a liberdade de participar ou não e de desistir a qualquer momento. Também foi assegurado o sigilo e 0 anonimato dos integrantes da prática.

\section{RESULTADOS E DISCUSSÃO}

$\mathrm{Na}$ análise da prática assistencial desenvolvida identificamos que estiveram presentes dois temas que estavam interligados: a percepção da tuberculose e seus cuidados e tratamentos e o isolamento social.

\subsection{A percepção da doença}

A percepção das pessoas acerca de sua condição de saúde orienta suas escolhas de cuidados e tratamentos, bem como a forma de conviver com a mesma.

As pessoas que fizeram parte do grupo de convivência percebem que a tuberculose lhes trouxe situações indesejadas, especialmente afetando seus relacionamentos, tanto aqueles mais próximos quanto com pessoas conhecidas.

A principal preocupação delas foi com a questão da transmissibilidade da doença. Esse foi um assunto recorrente em todos os encontros do grupo. Apesar de terem sido orientadas pelos profissionais de saúde ao ser estabelecido o diagnóstico da tuberculose, apresentaram muitas dúvidas sobre o processo de desenvolvimento da doença e sua transmissibilidade. Mesmo aquelas que diziam saber que não mais transmitiam, mantinham uma certa preocupação, evidenciando a falta de confiança nas informações que se misturavam aos seus conhecimentos prévios, mesmo que vindos de seus pais e avós, de um tempo onde não havia cura para a tuberculose. A fala a seguir evidencia essa questão: 
A máscara é assim, eu não tenho certeza, nem o sim, nem o não, o que pega e o que não pega. Até agora não pegou, mas que sabe daqui uns tempos... Então a máscara é uma prevenção, para prevenir que outros não vão se contamina (Machado de Assis).

Quando perguntados sobre o que é tuberculose, geralmente a definem a partir de sua manifestação: "É catarro". A percepção da origem da doença gera muitas controvérsias: há aqueles que acham que veio do cigarro, que veio de uma gripe mal curada, que é uma bactéria que está dentro da pessoa que se desenvolve, como pode ser observado nas seguintes falas:

Eu já tive gripe forte, que eu trabalhava assim no ar condicionado e saía e não tinha carro. Aí saia pro vento (... ) Então tu estás dentro de uma ambiente assim, com uma temperatura, daí tu sais... Na minha época, no ponto de ônibus não tinha cobertura, era tudo ao relento, daí pegava chuva. Então pegava aquela gripe. Daí tomava uma coisinha e nem dava muita bola para a doença. Ai foi acumulando, acumulando até que deu uma infecção e não curou mais. Na minha cabeça é isso. Castro Alves)

Eu acho, para mim é do cigarro. (...) Eu botei na minha cabeça que é por causa do cigarro. Botei a culpa no cigarro. (Castro Alves)

Eu acho que a gente tem uma bactéria dentro da gente que se desenvolve, a mesma coisa que o câncer (Machado de Assis).

O câncer foi trazido à discussão em dois momentos, comparando-o à tuberculose por alguns e outros contando como ficaram aliviados ao descobrirem que não tinham câncer, que o diagnóstico era de tuberculose.

A principal dúvida envolvida na compreensão do que é sua doença é sobre como "pegaram" a tuberculose. Não identificam uma possível fonte e também a época da contaminação. Essa dúvida, muitas vezes, manifestase como uma importante questão, parecendo que a descoberta dessa fonte de contaminação iria esclarecer muitas coisas para eles, poderia Ihes dar uma compreensão mais clara para como poderiam estar contaminando outras pessoas, ou até mesmo, que a doença pudesse se tornar algo mais concreto com a descoberta de sua origem.

Outra maneira que nos aproxima da compreensão que pessoas têm da tuberculose e de como se percebem como portadores da mesma, foram as imagens que construíram através de desenhos e colagens e para as quais deram as seguintes explicações:

É como uma florzinha que está tão bonitinha e começa a tirar as pétalas e ela vai se desmanchando. No inverno elas não florescem. Quem sabe terminado o tratamento começa a florescer novamente? (Álvares de Azevedo)

Sou como uma árvore, mas não tem folhas nem frutos.(Castro Alves) Eu sou um coração fechado. Porque estou doente, dá um aperto... (Machado deAssis)

Nesta percepção de si com a tuberculose, há uma imagem de algo que "secou", onde quase não há vida: a flor sem pétala, a árvore sem folhas e frutos, o coração fechado. Essas imagens possivelmente foram construídas a partir de suas vivências, por exemplo, de um emagrecimento acentuado, de sensações de mal estar, de isolamento social, mas também de um passado onde a tuberculose não tinha cura.

Apesar do número de pessoas que integraram o grupo ter sido restrito, nossas experiências profissionais com pessoas com tuberculose, evidenciam que elas trouxeram muito da problemática que envolve o viver com essa doença. Suas percepções ressaltam o preconceito que vivenciam, as noções distorcidas sobre contaminação e transmissão e também a falta de compreensão dos avanços científicos no que diz respeito aos cuidados e tratamentos. Vale ainda destacar que eram pessoas que faziam parte de um serviço de saúde referência para esta doença e todas já estavam em tratamento há algum tempo. Portanto, haviam recebido orientações sobre a tuberculose e os cuidados e tratamentos a serem efetuados. Isso nos trouxe alguns questionamentos sobre as formas como têm sido processadas as orientações e também como elas estão apreendendo e interpretando aquilo que é colocado pelos profissionais de saúde.

\subsection{Preconceito e Isolamento social}

Um dos aspectos mais destacados pelos integrantes do grupo foi a repercussão da doença em suas vidas. Já nos primeiros encontros a questão do preconceito foi trazida como uma conseqüência negativa da tuberculose, trazendo-lhes muito sofrimento e promovendo seu isolamento social.

Como já comentado no item anterior (A percepção da doença), a preocupação com a contaminação os faz sentirem-se excluídos pelas outras pessoas ou também elas próprias se isolam, numa reação que algumas vezes nos pareceu uma antecipação, ou seja, isolavam-se antes que fossem isolados.

Esse isolamento social era uma decorrência do preconceito que a doença ainda tem. Mesmo sentindo-se aliviados quando outros membros da família com os quais tinham contato íntimo apresentavam exames negativos, persistia o medo e a exclusão social, como pode ser observado nas seguintes falas:

No começo da minha doença meus filhos não chegavam perto de mim. Estava pedindo para morrer (...) Eles tinham medo de mim... Com aquela rejeição, o coração vai doendo mais ainda, porque estava sendo rejeitada, né? (... ) O meu marido veio aqui quando soube que eu realmente estava; ele fez os exames e não tinha a doença> Ele saiu e nunca $m$, ais voltou... nem perguntou se eu morri, nada. Pegou e foi embora. Achou que eu ia passara para ele, entendeu? (Castro Alves)

É um preconceito danado... eu tinha dois empregos, cuidava de um senhor com Alzheimer e outro no hospital... Quando a família soube, perdi o emprego. Isso porque a filha dele era enfermeira, que é uma pessoa esclarecida. Perdi o emprego, fiquei só no hospital. É um tratamento ruim que deixa a nossa auto-estima lá embaixo, não recebe visita, porque mesmo os parentes não acreditam. (Álvares de Azevedo)

O preconceito é que machuca... E eu, como profissional da saúde (Técnica de enfermagem)_eu achava que tratava bem as pessoas que ficavam no isolamento com tuberculose. A gente dava o remédio de manhã, arrumava o quarto. As vezes a pessoa ficava até o final da tarde sozinha. Imagina o que eles não sentiam. Eles não recebiam visita, porque quem está de fora não entra... Hoje eu vejo assim, com muita diferença isso... (Álvares de Azevedo)

Nas duas últimas falas, percebe-se que não apenas pessoas leigas desconhecem o processo saúde-doença da tuberculose, mas profissionais da saúde colocam seus preconceitos acima do conhecimento da biomedicina, evidenciando o quanto essas questões precisam ser trabalhadas na formação profissional.

Algumas pessoas usam estratégias para lidar com o preconceito, tal como ocultar o diagnóstico:

Eu não falo para ninguém, porque tem muito preconceito, ninguém precisa saber. (Machado de Assis)

A atitude de ocultar o diagnóstico é explicada por Goffman ${ }^{(19)}$ como uma estratégia de manipulação da informação. Há a preocupação em esconder o problema, principalmente em relação as pessoas mais íntimas das quais o indivíduo tem as reações negativas ${ }^{3}$. 
Uma das integrantes do grupo contou que ao conhecer o diagnóstico da tuberculose e perceber-se rejeitada pela família e por outras pessoas próximas, chegou a pensar em suicídio:

\section{Eu procurei o veneno de rato para me matar, porque estava me sentindo rejeita...(Castro Alves)}

De maneira geral, as pessoas que integraram o grupo trouxeram como um dos principais temas de discussão a exclusão social. Há entre elas a necessidade de reafirmação de que não constituem um risco para a sociedade, que podem conviver entre as pessoas e manterem seus relacionamentos. A dualidade entre sentir-se amado e sentir-se rejeitado, é um sentimento experimentado por todos. A superação dessa situação parece ser possível somente com a compreensão mais ampla e clara dos riscos que a tuberculose traz.

A divulgação do que é a doença, seus cuidados e tratamentos através da mídia e a orientação individual e coletiva promovida pelos profissionais da saúde, se colocam como as estratégias que podem trazer resultados mais efetivos para um viver mais saudável com a tuberculose.

\subsection{Reflexões sobre o Grupo de Convivência}

O trabalho educativo em grupo oportunizou às pessoas compartilharem seus saberes e suas experiências a respeito de cuidados de saúde. Por outro lado, o trabalho em grupo fortaleceu as potencialidades individuais e grupais, ampliou a visão de recursos disponíveis para as ações de saúde e encorajou os participantes a buscarem novas estratégias para enfrentarem os desafios. Na avaliação dos participantes:

"O grupo é bom porque a gente conversa né fica sabendo, mais, fica mais bem informado (Machado de Assis)".

"O grupo me ajudou a ver gente com tuberculose e me ajudou , como eu disse antes eu ia me matar e o grupo me ajudou, gostei muito do grupo, acho que devia continuar, é uma pena que os outros não querem.. (Álvaro de Azevedo)".

A troca de experiências e a percepção de que não vivem sua situação de maneira isolada, que os dramas que vivenciam são também experienciados por outras pessoas, parece trazer à elas mais força para lidar com a situação. Ao poderem falar livremente e acreditando que estão sendo compreendidos em toda a extensão de sua situação, sentem-se como que "reconfortados", amparados, e passam a acreditar que é possível viver melhor com seu problema de saúde. O fluxo das informações tornase mais livre, há uma abertura para a compreensão das informações sobre o tratamento, sobre as implicações de seguir ou não tomando as medicações.

No grupo de convivência, o profissional enfermeiro age como um facilitador do processo, mas também como aquele que dá uma certa direção, não no sentido da condução autocrática, mas uma direção proposta e acordada pelo próprio grupo. Há a necessidade de que o profissional mantenha-se atento ao que ocorre com cada um dos integrantes, que perceba o momento que cada um está passando e abra o espaço para as expressões, promovendo, de certa forma, que todos tenham oportunidade de se manifestar ou não. O profissional precisa estar atento para as monopolizações, para as exclusões, enfim, precisa compreender que a troca é livre/espontânea, mas ao mesmo tempo, decorrente de um processo de construção de espaços de expressão e de trocas.

Através das reflexões em grupo, seguindo os pensamentos de Freire, percebi que as pessoas se sentiram importantes por serem valorizados seus conhecimentos e opiniões, se sentiram úteis por ajudarem com 0 cuidado do colega.

Com relação à efetivação do tratamento, considerando que a amostra foi pequena, não houve desistência do tratamento, muito pelo contrário, através das falas percebe-se que de alguma forma o grupo contribuiu na efetivação do mesmo.

\section{"Aqui no grupo eu vejo outras pessoas também normal, então o grupo me ajudou bastante (Castro Alves)".}

"No grupo eu vi gente com tuberculose, eu nunca tinha visto ninguém tuberculoso (Álvaro de Azevedo)".

A assistência de enfermagem prestada às pessoas com tuberculose em grupo de convivência propicia uma maior interação, e ajuda a perceber que não estão sozinhos, que grande parte dos problemas que enfrentam no convívio com esta condição de saúde também é compartilhada por outras pessoas, possibilitando o entendimento das situações que vivenciam e propiciando formas criativas de superá-las.

\section{CONSIDERAÇÕES FINAIS}

Nest experiência, foi percebido que desenvolver uma prática educativa em grupo é favorável e permite que as pessoas ampliem a compreensão de sua doença, tanto no que diz respeito aos aspectos clínicos como também dos aspectos políticos e do processo de viver com a tuberculose.

O número reduzido de encontros não nos permite dizer que ele contribuiu para a superação de questões mais profundas como o isolamento social e o preconceito. Podemos dizer que houve indícios de que as pessoas estavam refletindo sobre isso e podendo estar num processo de reconstrução da percepção de sua condição de saúde.

Percebi com essa prática que a educação em saúde participativa, apresentou-se como fundamental estratégia para reflexão e discussão das situações de saúde, levando a tomada de consciência que conduz a um melhor enfrentamento das situações vivenciadas.

A implementação da atividade de grupo oportuniza um cuidado mais humano, o compartilhar ensino-aprendizagem e uma repercussão positiva sobre a qualidade de vida da população.

\section{REFERÊNCIAS}

1. Sontag S. A doença como metáfora. $3^{\circ}$ ed. Rio de Janeiro (RJ): Graal; 2002.

2. Nascimento DR. As pestes do século XX: tuberculose e Aids no Brasil, uma história comparada. Rio de Janeiro (RJ): FIOCRUZ; 2005.

3. Claro LBL. Hanseníase: representações sobre a doença. Rio de Janeiro (RJ): Fiocruz; 1995.

4. Bertolli Filho C. História social da tuberculose e do tuberculoso: 1900-1950. Rio de Janeiro (RJ): FIOCRUZ; 2001.

5. Bertazone ÉC, Gir E. Aspectos gerais da sexualidade dos portadores de tuberculose pulmonar atendidos em unidades

básicas de saúde de Ribeirão Preto-SP. Rev Latino-am Enfermagem 2000; 8(1): 115-22.

6. Ministério da Saúde (BR). Avaliação Epidemiológica e Operacional do Programa Nacional de Controle da Tuberculose 2005. Brasília (DF): Ministério da Saúde, 2005.

7. Ministério da Saúde (BR). Secretaria de Políticas de Saúde. Manual técnico para o controle da tuberculose: cadernos de atenção básica. 6ª ed. Brasília (DF): Ministério da Saúde; 2002.

8. Gonçalves H, Costa JSD, Menezes AMB, Knauth D, Leal OF. Adesão à terapêutica da tuberculose em Pelotas, Rio Grande do Sul: na perspectiva do paciente. Cad Saúde Pública 1999; 15(4): 
777-87.

9. Borges ZN. A Construção social da doença: um estudo das representações sobre 0 transplante renal.In: Leal OF organizadora. Corpo e Significado: ensaios de Antropologia Social. Porto Alegre (RS): Editora da Universidade;1995. p.363-77.

10. Mascarenhas MDM, Araújo LM, Gomes KRO. Perfil epidemiológico da tuberculose entre os casos notificados no município de Piriri, estado do Piauí, Brasil. Rev SUS 2005; 14(1).

11. Alonso IK. O processo educativo em saúde na dimensão grupal. Texto Contexto Enferm 1999; 8(1):122-32.

12. Freire $P$. Conscientização: teoria e prática: uma introdução ao pensamento de Freire. $3^{a}$ ed. São Paulo (SP): Moraes; 1980.

13. Freire P. Pedagogia do oprimido. Rio de Janeiro (RJ): Paz e Terra; 1987.
14. Freire P. Pedagogia da autonomia: saberes necessários à prática educativa. Rio de Janeiro (SP): Paz e Terra; 1988.

15. Dias LP, Trentini M, Silva DMGV. Grupos de Convivência: uma alternativa instrumental para a prática de enfermagem. Texto Contexto Enferm 1995; 4(1): 83-92.

16. Trentini M, Gonçalves LHT. Pequenos grupos de convivência um método no desenvolvimento de tecnologias na enfermagem. Texto Contexto Enferm 2000; 9(1): 63-78.

17. Trentini M, Dias LP. Ser-mais - uma possibilidade de promover saúde pela prática educativa. Acta Paul Enferm 1997; 10(2): 20-4.

18. Capella A. Cuidado: essência da enfermagem. Florianópolis (SC): UFSC;1999.

19. Goofman E. Estigma: notas sobre a manipulação da identidade deteriorada. 4a ed. Rio de Janeiro (RJ): LCT; 1988. 